\title{
The Influence of Leader-Member Relationship on Staff under the Feeling Trusted
}

\author{
Xue Yang \\ Department of Business Administration, Daejeon University, Daejeon, South Korea \\ Email: astronautyang@gmail.com
}

How to cite this paper: Yang, X. (2019) The Influence of Leader-Member Relationship on Staff under the Feeling Trusted. Open Journal of Business and Management, 7, 562-567.

https://doi.org/10.4236/ojbm.2019.72039

Received: March 5, 2019

Accepted: March 25, 2019

Published: March 28, 2019

Copyright (อ 2019 by author(s) and Scientific Research Publishing Inc. This work is licensed under the Creative Commons Attribution International License (CC BY 4.0).

http://creativecommons.org/licenses/by/4.0/

\section{(c) (i) Open Access}

\begin{abstract}
Through a survey of 256 employees and their supervisors, the results show that the leader-member relationship between the supervisor and the employee has a certain adjustment effect on the relationship between organizational input and employee contribution, which indicates that the role of the supervisor playing as a spokesperson of employees is indeed having an influence on the role of the organizational agent. When the supervisor thinks that the leader-member relationship is good, it can promote the smooth progress of social exchange between the organization and the employees, so that the input of the organization can get higher job performance returns and work engagement of the employees, but the emotional exhaustion between each other cannot be proved.
\end{abstract}

\section{Keywords}

The Feeling Trusted, Staff, Leader-Member Relationship

\section{Preface}

Employees are one of the most important stakeholders in the company. How to manage the relationship between the organization and employees is a topic of common concern in the circles of business community and academics. At present, the theory of social exchange has become the main theoretical framework for studying the employee-organization relationship [1] [2]. During the study on employee-organization relationship with different cultural backgrounds, it was found that the existence of social exchange process refers to the social exchange relationship between the organization's input to employees and the contribution of employees to the organization. Regarding the role of managers in it, 
BARNAR believes that the main responsibility of managers is to manage the balance between organizational input and employee contributions. This idea has been continued in many subsequent studies, because in addition to the owner who is directly managing the enterprise, the enterprise can only do social exchange with the employees through the agent. The agent of the organization may be the top management, human resources department or direct supervisor, and the direct supervisor is considered to be the most critical agent. For example, as the key to the implementation of human resource management, middle-level managers must translate the goals and expectations of the organization into acceptable provisions for employees, and also convey the requirements and expectations of employees to senior managers.

Managers play a dual role. Managers (especially middle-level managers) often face strong role conflicts due to inconsistencies between organizational expectations and employee personal expectations. Therefore, one of their roles may have an influence on the performance of another role. In a social environment in China that values relationships, leader-member relationship is likely to affect the smooth execution of social exchanges between organizations and employees. But so far, the domestic and international theoretical circles have conducted a lot of studies on staff and leader-member relationship. The studies are almost all carried out separately, ignoring the possible influence of the leader-member relationship on the staff. This paper is to make up for this deficiency, because for the organization, whether the manager can really play the role of the organizational agent is very important. Therefore, based on the theory of social exchange, through the paired survey of 256 employees and their supervisors from more than 10 enterprises, the influence of the leader-member relationship on the staff reported by the supervisors and the employees was studied.

\section{Theory and Assumptions}

To explore the influence of leader-member relationship on staff, it is first necessary to understand what is the specific content of staff input and employee contributions, and what is the relationship between employee input and employee contribution when not considering the influence of leader-member relationship. Regarding the relationship between developmental input and performance, some studies have found that authorization has a positive influence on task performance, while the relationship between career management, participation in decision-making, fairness and employee task performance are still unclear. Some studies have found that there is a positive relationship between them. However, others find that there is no correlation. For example, it is found that organizational career management is not related to employee task performance. Long Lirong and others found that the organizational career management of Chinese enterprise has a positive influence on the task performance of employees. In developmental input, employees' perception of fairness has a positive influence on organizational citizenship behavior. When employees' values are more modern, 
the influence is stronger. The study found that the positive relationship between leaders and members regarding the emotional exhaustion of employees is not obvious. Figure 1 below is a theoretical hypothesis induction.

Hypothesis 1: The leader-member relationship has a positive influence on employee task performance and work engagement.

Hypothesis 2: The quality of leader-member relationship has a positive influence on employee emotional exhaustion.

\section{Study Methods}

In order to verify the above hypotheses, the author compiled a questionnaire for employees and their direct supervisors, and conducted a questionnaire survey of 675 employees and their supervisors in 35 enterprises. The questionnaire has been reviewed by the expert group.

Each supervisor fills in the questionnaire for the case of 1 2 subordinates [1] [2] [3]. The supervisor mainly reports the organization's input to a certain subordinate compared with colleagues at the same level, the subordinate's emotional aspects, task performance and work engagement, and his leader-member relationship with this subordinate. Employees mainly report their own leader-member relationship with the direct supervisors, as well as their own work situations. The survey collected the effective questionnaire filled out by a total of 256 employees and their 204 supervisors, and the comprehensive recovery rate of the questionnaire was $41.5 \%$.

\section{Measurement Tools and Their Validity and Reliability}

This paper uses the mature scale as a measurement tool, and analyzes the reliability and validity with Cron-bach a coefficient method and confirmatory factor analysis (CFA).

The specific measurement methods for each variable are as follows:

1) For the Job performance and work engagement, the single-dimensional task performance scale in employee-member relationship strategy study such as TSUI is used. In the questionnaire, the supervisor is asked to judge the relevant description for the specific subordinates (for example, the degree of consent for "the quality of the work completed is much higher than the average level"), 1 point

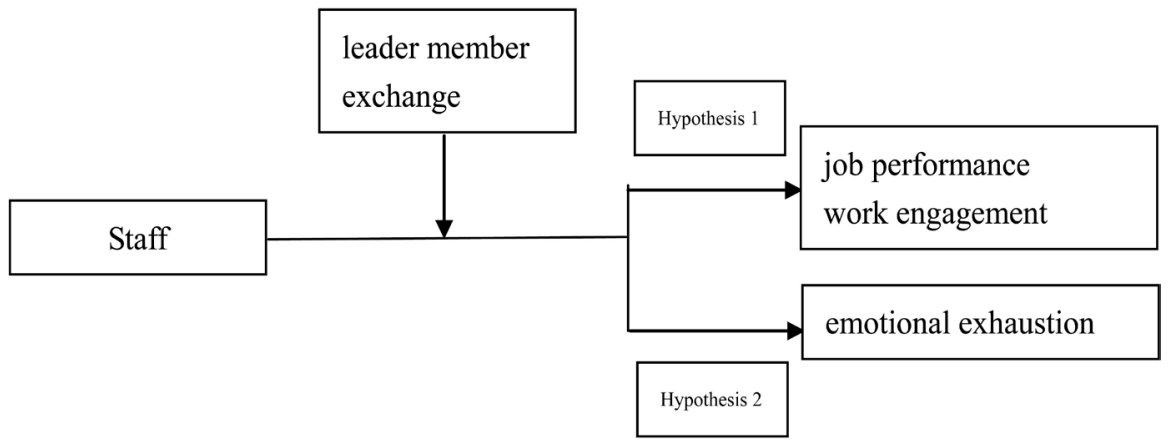

Figure 1. Theoretical hypothesis induction. 
represents complete disagreement, and 7 points represent full agreement.

2) For the emotional exhaustion, the organizational commitment scale developed by Ling Wenquan et al. is used [1]. It includes three dimensions: emotional commitment, normative commitment, and ideal commitment. In the questionnaire, employees are asked to answer about their consent degree to the description of some work experiences (such as "I am willing to contribute my spare time to the company" and "I am willing to stay in the company because the job is conducive to achieving my ideals", etc.), 1 point represents complete disagreement, and 7 points represent full agreement.

3) For the leader-member relationship, although the structure of the leader-member relationship is still single-dimensional or multi-dimensional, it is still controversial. However, since the main concern of this paper is the quality of the leader-member relationship rather than the exchange content, the single-dimensional resistance 1 scale with good reliability and validity is adopted. This scale has 7 problems, related to the quality of the leader-member relationship measured by the localization multi-dimensional scale developed by Wang Hui et al. In the questionnaire, managers and employees are asked to answer about their consent degree to the description according to their work experiences (such as "I fully understand his difficulties and personal needs in work" and "The work relationship between I and this subordinate is very harmonious, so our work is efficient and accomplished", etc.), 1 point represents complete disagreement, and 7 points represent full agreement [4].

\section{Results and Discussion}

The path analysis of the structural equation model (using LISREL 8.54 software) is used to verify the hypothesis 1 and hypothesis 2 . The selection of the overall fit goodness indicator is consistent with the aforementioned confirmatory factor analysis. Before computing, the topics of the same dimension of the organizational commitment and organizational citizenship behavior are averaged into one indicator. After the merger, the organizational commitment becomes a latent variable with three indicators. The organizational citizenship behavior becomes a latent variable with five indicators (the same below).Because of the different nature of these two types of inputs, we will first examine the influence of these two types of inputs on employees separately, and then examine the joint role of the two.

This paper finds that there is a certain incentive effect when considering the influence of the adjustment role of the leader-member relationship on the employee performance and work engagement. Among them, the influence on employee performance is stronger, and the influence on the organizational commitment to employees also exists. This means the leader-member relationship can only encourage employees to perform better, but not increase employees' loyalty. In other words, it is difficult to exchange employee commitments to the organization solely by performance pay and bonuses. This result verifies Hertzberg's 
two-factor theory to some extent through questionnaire data. In addition, the results of the study cannot confirm that the adjustment role of leader-member has a positive effect on staff's emotional exhaustion [3] [4].

The contribution of this paper is mainly to verify the influence of the leader-member relationship of supervisor and employee reports on the staff, in enterprise confirm that the influence of organizational input on employee contributions depends on the leader-member relationship, also find that the leader-member relationship of supervisor and employee reports has different adjustment role on the relationship between organizational input and employee contribution.

The shortcoming of this paper is the use of cross-sectional data study, so it is difficult to examine the process of leader-member relationship interfering with the staff, and the process of interaction between organizational input and employee contribution. Both of these processes require a certain time interval to complete [4] [5] [6]. Thus, subsequent related studies can try to use the longitudinal study design. In addition, this paper examines the influence of the role of business managers in their work situations as the employees' spokesperson on the social exchange of employees and organizations in which they involve as an organizational agent, and also the influence of one social exchange relationship on another social exchange relationship in the organization. In fact, managers also as employees participate in their social exchanges with organizations, and face conflicts of interest between organizations, themselves and their subordinates in multiple social exchange roles. These conflicts and the behaviors of managers in conflict situations need to be further explored and studied.

\section{Conclusion}

This paper examines the influence of the role of business managers in their work situations as the employees' spokesperson on the social exchange of employees and organizations in which they involve as an organizational agent, and also the influence of one social exchange relationship on another social exchange relationship in the organization.

\section{Conflicts of Interest}

The author declares no conflicts of interest regarding the publication of this paper.

\section{References}

[1] Barnard, C.I. (1938) The Functions of the Executive. Harvard University Press, Cambridge, 145-157.

[2] Farh, J.L., Earley, P.C. and Lin, S.C. (1997) Impetus for Action: A Cultural Analysis of Justice and Organizitional Citizenship Behavior in Chinese Society. Administrative Science Quarterly, 42, 421-444. https://doi.org/10.2307/2393733

[3] Hooper, D.T. and Martin, R. (2008) Beyond Personal LMX Quality: The Effect of Perceived LMX Variability on Employee Reactions. Leadership Quarterly, 19, 20-30. 
https://doi.org/10.1016/j.leaqua.2007.12.002

[4] Long, L.R., Fang, L.L. and Ling, W.Q. (2002) An Empirical Study of Organizational Career Management and Its Effects. Journal of Management Science in China, 5, 61-67.

[5] March, J.G. and Simon, H.A. (1958) Organizations. Wiley, New York, 103-104.

[6] Tsui, A.S., Pearce, J.L., Porter, L.W., et al. (1997) Alternative Approaches to the Employee-Organization Relationship: Does Inducement in Employees Pay off? Academy of Management Journal, 40, 1089-1121. https://doi.org/10.5465/256928 